\title{
Transatlantica
}

Revue d'études américaines. American Studies Journal

Line Breaks in America: the Odds and Ends of Poetry

\section{Emily Dickinson's Line Breaks in Her Envelope Poems}

\section{Antoine Cazé}

\section{(2) OpenEdition}

1 Journals

\section{Electronic version}

URL: https://journals.openedition.org/transatlantica/16884

DOI: 10.4000/transatlantica.16884

ISSN: $1765-2766$

\section{Publisher}

Association française d'Etudes Américaines (AFEA)

\section{Electronic reference}

Antoine Cazé, "Emily Dickinson's Line Breaks in Her Envelope Poems", Transatlantica [Online], 1| 2021, Online since 01 July 2021, connection on 31 January 2023. URL: http://journals.openedition.org/ transatlantica/16884; DOI: https://doi.org/10.4000/transatlantica.16884

This text was automatically generated on 31 January 2023

\section{(c) (i) (9)}

Creative Commons - Attribution-NonCommercial-NoDerivatives 4.0 International - CC BY-NC-ND 4.0 https://creativecommons.org/licenses/by-nc-nd/4.0/ 


\title{
Emily Dickinson's Line Breaks in Her Envelope Poems
}

\author{
Antoine Cazé
}

\section{AUTHOR'S NOTE}

Credits: Transcriptions by Jen Bervin and Marta Werner, from GORGEOUS NOTHINGS, copyright $\odot 2013$ by Jen Bervin and Marta Werner, copyright $\odot 2013$ by Christine Burgin and New Directions. Transcriptions used by permission of New Directions Publishing Corp.

\section{Introduction}

1 In her introduction to The Gorgeous Nothings-a selection of poems written on envelopes by Emily Dickinson in the later part of her life, falling into a category of texts still known to many Dickinson scholars as "scraps"-visual artist and poet Jen Bervin reminds us quite relevantly that "Dickinson's envelope writings convey a sense of New England thrift and their relationship to the larger household economy of paper, but they also disclose private spaces within that household [...]." (Bervin \& Werner 9). Bervin's attention paid to the material economy of Dickinson's writing on such a particular medium as recycled envelopes here reinforces Alexandra Socarides' assessment of the ways in which the American writer's poems generally relate to their surfaces of inscription: "Dickinson is a writer," the scholar argues in the conclusion of her study of Dickinson's material poetics, "who invites us to look at her paper in part because she explicitly writes about how it shapes what she has to say. [...] Aware of the contours of the paper, Dickinson wrote both with and against them" (Socarides 168). Socarides, however, does not consider the envelopes on which Dickinson wrote to be essentially different from any other loose sheet of paper the poet also used throughout her life. More specifically, while she notes how the shapes and texture of the paper interact with the meaning of Dickinson' words written on them, in such a way that 
"there is always something about the lines that makes it impossible for us to fully collapse the two things" (Socarides, 162), she does not point out the epistolary nature of envelopes as significant to Dickinson's practice. Bervin, on the contrary, ties the relationship between the poems and their surface of inscription to what is at stake in an epistolary mode of circulation and production.

2 Envelopes are indeed a very specific kind of paper surface, not just any odd scrap of paper, and using and reusing them for new writing does question the potency and potentiality of privacy for Emily Dickinson. Bervin's "private spaces" resonate with Dickinson's secret practice of writing, which led her to keep a great deal of her poems closeted within the confines of her bedroom till she died, while sending some of them out into the world, privately enclosed in letters addressed to select correspondents. The notion of privacy gains further relevance when considering the specificity of these so-called "scraps," poems Dickinson penned on the envelopes of letters she received, rather than poems she placed in envelopes with the letters she sent-the latter being a practice that was hers throughout her life. She thereby either tested out poems in the making before stabilizing them in a version she would then copy into her hand-made fascicles, or conversely reopened poems that she had copied out by showing them to privileged readers, her correspondents. By contrast, the containers of words that envelopes are-on which the only written words do not, under normal circumstances, carry any meaning beyond serving as directions for the words inside to be delivered and giving indications regarding whence these words originate-were repurposed as surfaces of writing; as if the privacy of the words inside, once the envelope had been opened and, as we shall see, torn apart, flattened out, cut into odd shapes, were simultaneously exposed and kept in the secret limbo of uncirculated rough drafts of poems to come, poems which themselves would remain for the most part locked in Dickinson's bedroom. As noted by Socarides in her discussion of Dickinson's peculiar and specific correspondence with Thomas Wentworth Higginson, starting in the Spring of 1862 , the poet "was able to play with the tension between public and private communication that is activated in both poetry and epistolary correspondence" (Socarides 53). This tension is increased in Dickinson's envelope writing, literally blurring the line between poetry writing and letter writing in a rather unconventional manner. My main focus in this article will therefore consist in examining the ways in which Dickinson's peculiar envelope writing can be seen as a metapoetic embodiment of how she "combined practices, defied conventions, and tapped into the permeability of both [the poetic and the epistolary] modes of writing" (Socarides 51).

\section{"Odd Secrets of the Line to Tell"}

Bervin and Werner's choice to bring together Dickinson's envelope poems within the covers of one book-an interesting way of binding those loose scraps into a corpus of texts related by their material circumstances-is a strong editorial intervention which challenges the predominantly printed manner in which Dickinson's texts have been handed down to posterity. In a sense, this break in the editorial line gives resonance to the kind of line break performed by the envelope poems themselves, keeping the visual appearance of The Gorgeous Nothings on the cusp between textuality and visuality. ${ }^{1}$ Paying close attention to the ways in which Dickinson composed her unusual writing spaces, by remodeling the initial, and initially limited/limiting, shape of the envelopes 
she used, like so many sandboxes for her poetic experiments, Bervin's introduction shows how it is all a question of negotiating and redrawing lines in order to define (literally, to assign limits to) the appropriate, differently domestic, space necessary for "the velocity of mind" that characterizes Dickinson's thinking. "Often," Bervin notes of the material characteristics found in the envelope poems, "she invents columns, typically two, to further divide the space, demonstrating a propensity to break poem lines shorter and shorter. She draws additional line segments or arcs to further divide the compositional space. One would think that such a space would feel carved up, crammed, but it doesn't. The page feels bigger yet, as if there has been an insertion of space" (Bervin \& Werner 10). The visual artist is led to read, or look at, those lines in pictorial fashion: the page, actually not a page in the conventional sense but rather a surface of writing, becomes a canvas on which the arrangement of lines-crucially including, for Dickinson, the smaller lines of her dashes incising the surface in strategically unpredictable places-creates fields of meaning, delineating the shape of a poem-to-be. In her Dickinson Composite Series (fig. 1), Jen Bervin has produced "largescale embroideries" that "depict the poet Emily Dickinson's variant marks in her manuscripts." Like several commentators, most prominently Susan Howe, Bervin insists on seeing the markings scattered across Dickinson's manuscript pages-small crosses, dashes of various lengths positioned at different angles on the lines, apparently random lines and curlicues-as an integral part of her writing process, totally overlooked (at least in their material particularity) in print editions, "which also override her line breaks." For her, the question of line breaks is therefore crucially linked to the more general issue of visual marks in Dickinson's poetry.

Fig. 1

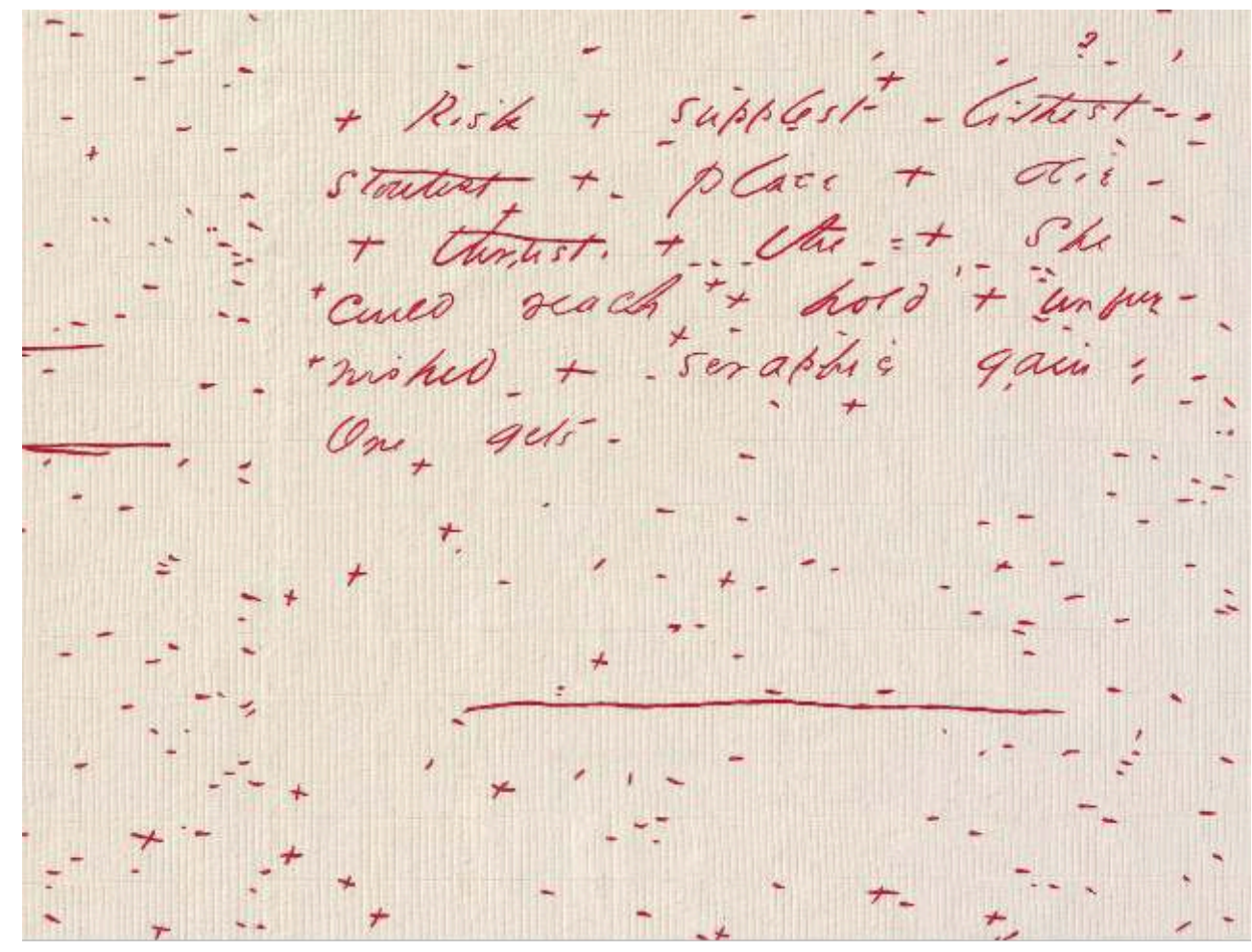

Jen Bervin, from The Dickinson Composite Series ${ }^{3}$ 
The drawing of lines within the context of fragmentary poems certainly participates as much as the writing of lines in Dickinson's larger experiments in shaping, and radically unsettling, or scattering, the relationships between modes and surfaces of writing, blurring any clear distinction which editors and publishers would love to maintain between poetry, letters, and drafts; fair copies and loose sheets, fascicles and sets; finished scraps vs. unfinished poems teeming with variant words.. "[Dickinson's] manuscripts should be understood as visual productions," asserts Susan Howe (Howe 1993).

Such a statement suggests that, most certainly for Howe and Bervin, as well as for many Dickinson scholars, ${ }^{5}$ this poet's work was never made to be read in print form, and that the visual, rather than scriptural, component rules her manuscript composition; or, to put it in a wider perspective, that in Dickinson's mode of composition, the scriptural tends to be subsumed under the larger category of the visual. As the book scholar Jerome McGann writes, "Emily Dickinson's poetry was not written for a print medium, even though it was written in an age of print" (McGann 38). Writing about Susan Howe's own poetics, which owe so much to Dickinson's, Will Montgomery has emphasized the "invidious status of manuscripts and the abilities of these artifacts to convey by visual means dimensions of writerly activity that are lost to the printed page" (Montgomery 117). This remark is of crucial importance for a study of line breaks in Dickinson's poems in general, and in this corpus of envelope poems in particular, insofar as they present an exacerbated case of a more general condition of writing characterizing Dickinson's oeuvre. As Bervin again remarks in her introduction to The Gorgeous Nothings, "Dickinson's manipulation of textual space is elastic in the manuscripts: her sprawling headlong letterforms, ambiguous capitalization, gestural punctuation, scale shifts in variant words, extremely short lines, and expansive spatial placement of words on the page trouble even a visually minded transcription" (Bervin \& Werner 11-12). On such a small, apparently limited space as that of an envelope, these characteristics defy the very possibility of visualizing, not to mention understanding or rationalizing, what a poetry line can actually be.

A study of the line breaks in this corpus of texts should therefore take into consideration the interaction of several issues. Firstly, line breaks can no longer be a mere matter of poetics, more specifically of metrics, but are crucially determined by material constraints out of which a poetics of the line may emerge, a poetics that calls into question the role measured lines play in defining poetry; a poetics which particularly challenges the pivotal role of the line break as the primary mode of distinguishing verse from prose. In "The End of the Poem," Giorgio Agamben has proposed a definition of poetry contra prose according to the line break as a superstructural characteristic:

Awareness of the importance of the opposition between metrical segmentation and semantic segmentation has led some scholars to state the thesis (which I share) according to which the possibility of enjambment constitutes the only criterion for distinguishing poetry from prose. For what is enjambment, if not the opposition of a metrical line to a syntactical limit, or a prosodic pause to a semantic pause? "Poetry" will then be the name given to the discourse in which this opposition is, at least virtually, possible; "prose" will be the name for the discourse in which this opposition cannot take place. (Agamben 109)

If one follows this compelling argument, by which the Italian philosopher claims that the surest way of defining poetry is the enjambment, i.e. the possibility of undoing (or 
overriding) line breaks by means of a tension or contra/diction between metrical and syntactical units, then the kind of line breaks induced primarily by the material constraints of both the characteristics of the handwriting and the surface of inscription, such as is the case in Dickinson, introduces an entirely new repertoire of definition as far as poetry is concerned.

7 Secondly, "line breaks" also refer here to another type of line being broken: the trajectory of texts that weave their way in and out of an epistolary mode, itself turned into an experimental writing laboratory by the transformation of the envelope from container of significant (private) words to surface of poetic inscription, overexposed by turning the textual material inside out, like a pocket being emptied out on a (writing) desk. ${ }^{6}$ From this redrawing (or readdressing) of lines emerges a fluid, dynamic body of texts, compounding their undefined status by an unstable, provisional, shifting use of the line and its various breaks-a "processual" kind of writing that cannot be rendered in print, as Dickinson scholar Roland Hagenbüchle once suggested in a seminal article: "Despite its careful annotation of textual variants, Thomas $\mathrm{H}$. Johnson's standard edition creates a false impression since his editorial decisions [...] tend to erase what is a crucial feature of Dickinson's poetry: its processual quality" (Hagenbüchle 15, emphasis added). ${ }^{7}$ The practice of line breaks thus becomes central for Dickinson in defining a general, and generally deviant, poetics in which epistolary, scriptural and visual determinants all play a contributing part, reflecting Dickinson's probe into what Jed Deppman has aptly called her "difficult projects of thinking" (Deppman 53).

In one poem, Dickinson's speaker mentions that he or she has "Odd secrets of the line to tell":

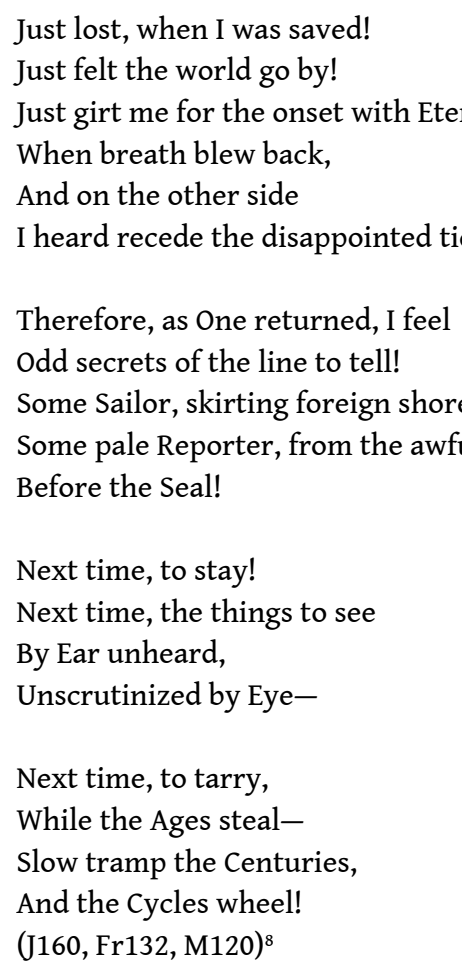

This poem is among those preserved by Dickinson in her fascicles-the thirteenth poem in Fascicle 10, written ca. $1860-61^{9}$-and does not show any of the untraditional visual features characterizing the later envelope poems, except for the occasional return where the lines are too long to fit on the page's width (lines 3, 6, and 10). Like many others, the poem describes what might be interpreted as a near-death experience in 
simultaneously religious and poetic terms but, beyond such a metaphorical proximity to be found throughout Dickinson's writings, ${ }^{10}$ what interests me more specifically here is the topological distortion shaping a world which is both narrowly familiar and distended to cosmic proportions. Rich in circumferences, hemispheres, dramatic changes of scale and unconventional perspectives "further than the sun" (J1074, Fr1124, M704), Dickinson's mental universe seems to refuse willfully to fit the constraints imposed by its own short forms-or "narrow" forms, to use a favorite adjective of hers. Typical in "Just lost, when I was saved!" is the pendular movement out to the extreme limits of experience and back to a center of consciousness that is durably altered to the point of feeling the urge to tell without quite being able to: "It is the Ultimate of Talk - / The Impotence to Tell -", the last two lines of "If What we could - were what we would -" (J407, Fr540, M295) ambiguously state. The envelope poems push this topological characteristic to an extreme by embodying that metaphorical "line" in their material characteristics. Interestingly, the maritime metaphor at the heart of that poem, "Some Sailor, skirting foreign shores!" (line 9), is also central in the first "envelope poem" included in The Gorgeous Nothings, "A great Hope fell" (J1123, Fr1187, M553)-a poem marked by the same doubts about the possibility to account for a "secret."11

\section{"founde/ring // at/Sea": Adjacency and Line Breaks}

In order to analyze the "odd" spaces paradoxically opened up by Dickinson's confined surfaces of writing, let us now look more closely at some examples-literally watch the page and its various breaks-reproduced in The Gorgeous Nothings, to try and assess what is going on in these uncommon artifacts that Dickinson left us as part of her double challenge to textual condition and literary interpretation. ${ }^{12}$

I shall first consider the first envelope poem in Werner and Bervin's facsimile edition (Werner \& Bervin 16-17, fig. 2). 
Fig. 2

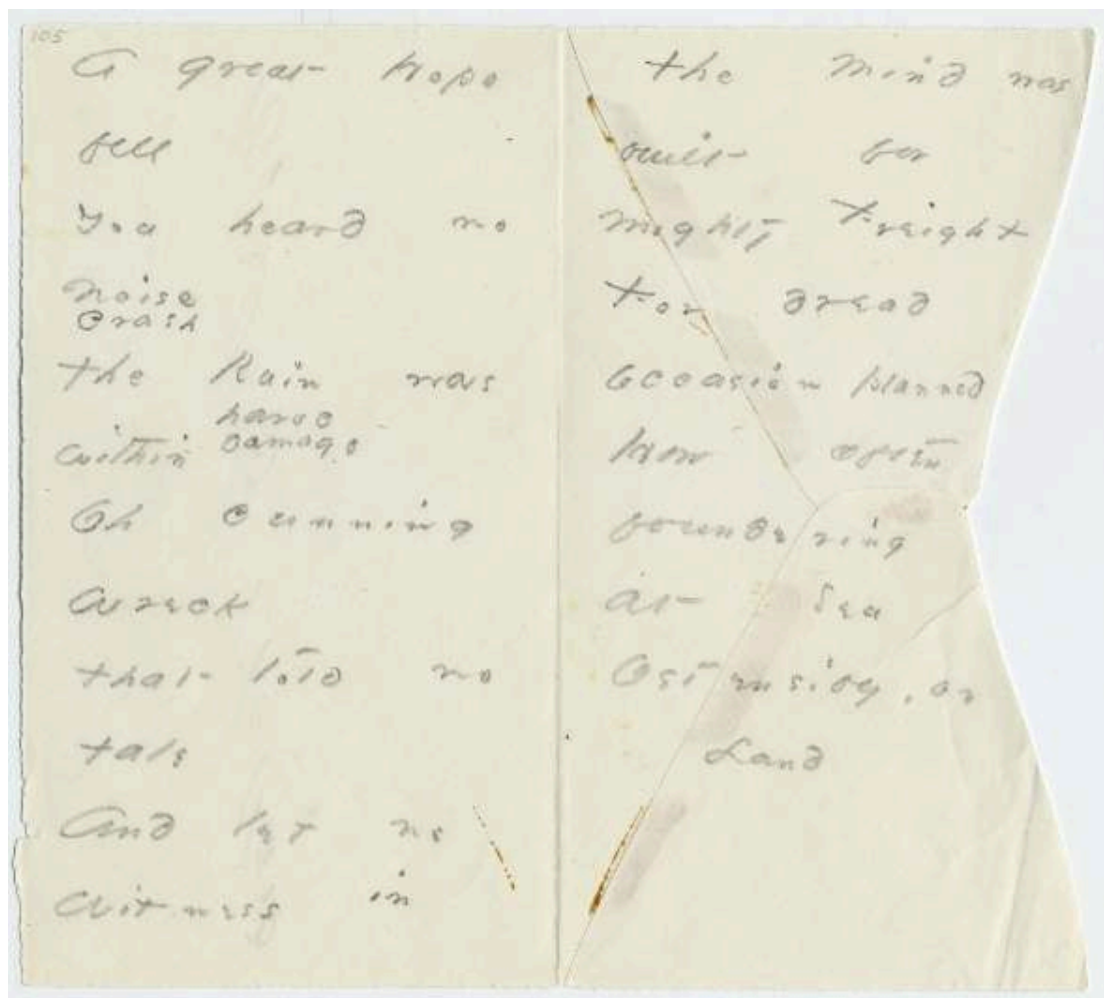

Emily Dickinson, "A great Hope fell". The Gorgeous Nothings. The Envelope Poems of Emily Dickinson (courtesy of New Directions).

11 On the face of it, this is a rather tidy poem by Dickinson standards and yet the lineation differs so radically from what a print transcript looks like (or I should say, can only look like). of the three existing modern scholarly editions, Cristanne Miller's rendition shown below is probably the one that comes closest to the original, and yet it misses some essential features of it, most blatantly the visual (as opposed to metrical) line breaks imposed by Dickinson's choice of using the two back and front flaps of the envelope as two columns:

\begin{tabular}{|l|r|}
\hline A great Hope fell & \\
You heard no noise & \\
The Rain was within & \\
Oh cunning Wreck & \\
That told no Tale & \\
And let no Witness in & [no] crash \\
The mind was built for mighty Freight & [The] havoc $\cdot$ damage \\
For dread Occasion planned & \\
How often foundering at Sea & \\
Ostensibly, on Land & \\
(Dickinson 2016 M553) & \\
\hline
\end{tabular}

12 However rational Dickinson's decision for choosing such a peculiar layout might lookindeed, given how spread out the poet's handwriting is, writing the lines across the 
width of the flattened out envelope would probably not have provided enough space for the whole poem to fit-it transforms the whole by creating a visual rhythm of line breaks. On the left hand side of the envelope, we see Dickinson artificially pulling the last word of each metrical line back to an initial position, tugging the eye away from the vertical crease that breaks the page down the middle. Such a spatial arrangement provides a visual counterpart to the heavy final stress falling on the monosyllabic end words ("fell," "noise," "Wreck," "Tale"). It also brings out the relationship between "within" and "Witness in" beyond the rhyme: once we start seeing the page, we become aware not only of the final "in" but also of the initial "wit" linking the two, which in turn allows the possibility of granting the syllable "ness" a life and meaning of its own, as if it gained a logical stress instead of a prosodic one. Lastly, the page layout (rather than the lineation, properly speaking) underscores the repetition of "no" three times (lines 2, 5 \& 6); and in the case of line 5-once a pattern of breaks has been establishedone feels that Dickinson is playing with the constraints of the medium, since the word "Tale" could easily have fitted on the same line if "no" had not been pushed farther than necessary to the right side of the "page." That such a play with the physical limits of the medium be the result of a conscious decision is confirmed by Dickinson's practice in her earlier correspondence with Samuel Bowles, for example. There, as Socarides has noted, "while she often placed a poem within the text of the letter, Dickinson was careful to mark it as a poem. For instance, the manuscript of her letter of early 1862 (L251) indicates that Dickinson indented the beginning of each stanza and attempted to hold each line of the 'Through the strait pass of suffering -' (F187) intact, for when she had to turn the line, she left the rest of that line blank" (Socarides 56). In a reverse manner, when writing "A great Hope fell," Dickinson blurred the limits between the lines. Not having to clarify anymore, now that the poem stands alone written on an envelope emptied of the letter it initially contained, Dickinson feels free to compose "by field," to take up and antedate a concept promoted by Charles Olson in the early 1950s, thus making the interaction between the lines and their physical space of inscription an integral part of the poem's meaning. ${ }^{13}$ Just as her errant capitalization blurs the beginning of lines, the composition lets shifting clusters of letters-i.e. syllables, which are so important to Olson as well ${ }^{14}$-surface in this non hierarchic space, such as the "in" of "Ruin," "within," "cunning,' and "in" concluding what may still be called a stanza. By the same virtue of field composition, the two -ing forms of the poem-"cunning" and "foundering"-appear side by side across the vertical fold running down the middle; together, they stand out as the central "line" of the entire poem, a characteristic that is totally lost in any standard print rendering. And yet, in the manuscript this serves to reinforce the semantic parallel between "cunning Wreck" and "foundering at Sea," which is the metaphorical backbone of this depressive poem about a "falling," or failing, Hope: on the envelope, "Wreck" faces "at Sea" in an immediately perceptible way, like a visual unfolding of the meaning, just as the envelope was flattened out to expose its contents. In another such echo across the vertical axis of that dividing line, "on" in the last metrical line of the poem (or penultimate visual line) reverses the facing "no" of the penultimate line on the left hand side column. The correspondence and a certain measure of continuity between the two columns are thus heightened by the line breaks, but their differences are also staged. While a certain regularity of additional line breaks prevails over the left side, corresponding to the back of the envelope whose paper is one single expanse, the right side is much more visually chaotic, so much so that the line breaks appear to be 
blurred. Paradoxically, however, when transcribed in conventional lines according to metrical rules, instead of spatial constraints, this second stanza reads more traditionally regular than the first: it turns out to be translatable, one might say, into a common meter quatrain $(4 / 3 / 4 / 3)$. Meanwhile, the multiple flaps of the envelope's front side create additional oblique lines that slash through the words, introducing a new type of line break in the field of vision. Just as Dickinson played more consciously with the line breaks in the left hand side stanza towards the end of the sheet, so here on the right. The word "foundering" is ostensibly cut at an illogical point (founde/ring instead of the more expected founder/ing), suggesting that the verb itself is sinking, lost in a sea of signs and paper, broken on a line of reef at the narrowest straits of the page-scape. Expanding the effect, Dickinson widens the gap between "at" and "Sea," each neatly scripted on either side of the dividing line, leaving a sinking space in the middle (retrospectively, one may observe the same blank in the line above, "How often"). "Ost/ensibly" reverses the proportions of "founde/ring" while playing the same non-etymological game. As for the last and apparently saving word, "Land," it leaves the left half of that line blank, widening the distance from "Tale" on the far left, and imparting the poem with a sense of imbalance: instead of finding our feet securely on that Land, we might fall down into the final blank space left vacant at the bottom of what we can no longer call a page. One might return here to Agamben's reflection on the end of the poem properly speaking, by contrast with the end of the lines during the course of the poem. Agamben speculates about what happens with the last line, which by definition does not allow a return to a next line but is destined to open onto the gaping void (or silence) that follows the poem:

What is this falling into silence of the poem? What is beauty that falls? And what is left of the poem after its ruin? If poetry lives in the unsatisfied tension between the semiotic and the semantic series alone, what happens at the moment of the end, when the opposition of the two series is no longer possible? Is there here, finally, a point of coincidence in which the poem [...] joins itself to its metrical element to pass definitively into prose? The mystical marriage of sound and sense could, then, take place. Or, on the contrary, are sound and sense now forever separated without any possible contact, each eternally on its own side? [...] In this case, the poem would leave behind it only an empty space in which, according to Mallarmé's phrase, truly rien n'aura eu lieu que le lieu. (Agamben 114, ellipses mine)

These words resonate strongly with the silence haunting Dickinson's "Hope" which itself fell into silence (lines 1 and 2); the dark destiny of this last line-in which "Land" does not provide any new hope, with the word "Land" floating unattached in that seaamplifies the meaning of a despair that can never be told, sealed from any communication with the outside, and therefore metaphorically "foundering at Sea" even when on "Land." ${ }^{15}$ Simultaneously, the choice of an envelope to write this poem about such a radical isolation appears even more relevant, for the poem's words can never be in touch with any epistolary prose the envelope once contained. The last line and the ensuing blank seals off the poem in the absolute privacy of a spectral epistolary mode, deprived of any addressee; the internal "Wreck" must remain silent, its broken lines a sign of how impossible it is to testify to it. Dickinson therefore suggests, by choosing an envelope as the surface of inscription for the topological paradox of an inner ruin, the thwarted continuities between poetry and letter, exposing on the outer, empty shell of the envelope the inner struggle of the mind, thus reversing the values of public and private spaces. 
By contrast, in the next envelope poem presented in The Gorgeous Nothings Dickinson adopts an entirely different page strategy, even though the envelope she used is spatially similar to the previous one. Indeed, this time she confines the writing to the back flap of the unfolded envelope, giving the impression that the poem has imploded and crashed upon itself. This befits the general meaning of the poem, depicting the collapse of the poem's persona, a mental shutdown eventually leading to a figurative death (Werner \& Bervin 20-21, Fig. 3).

Fig. 3

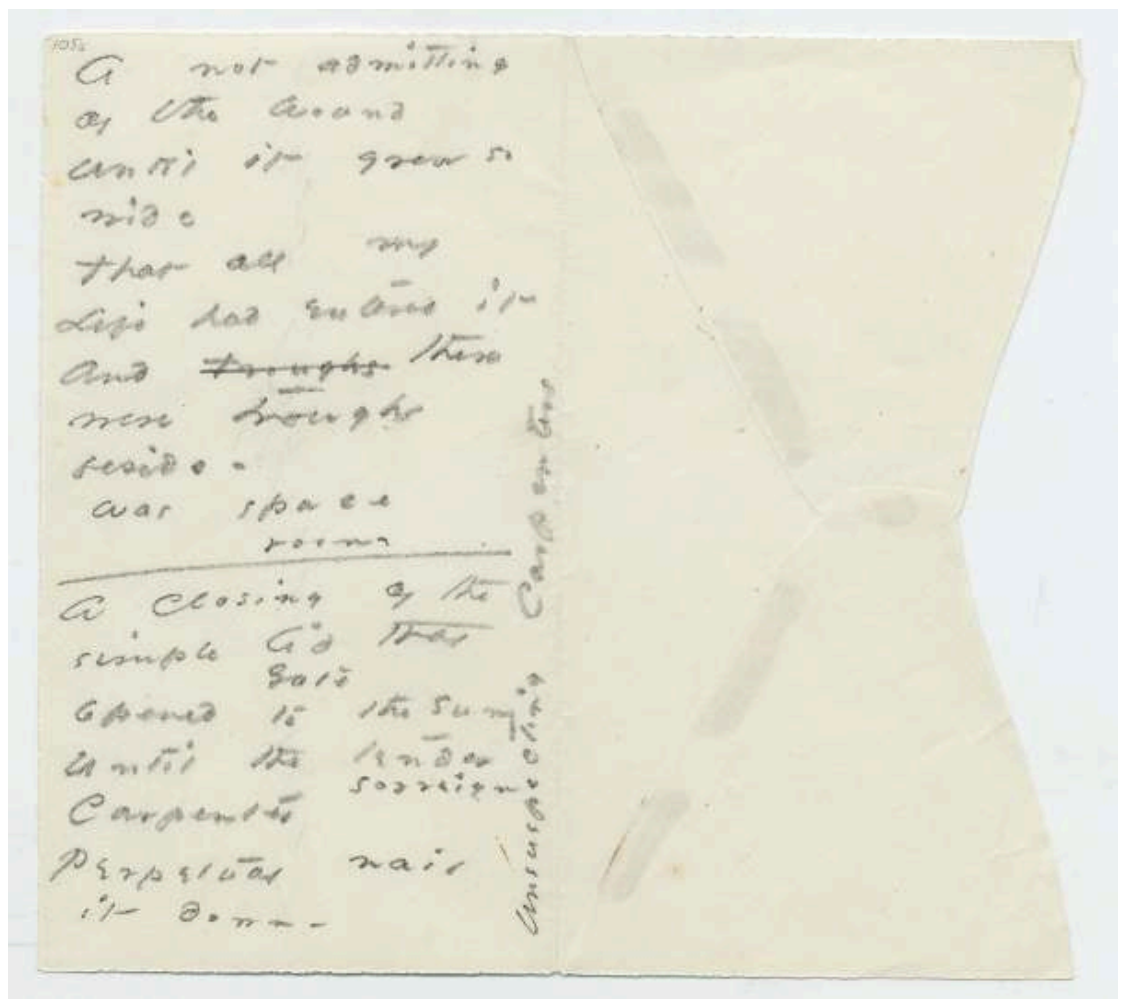

"A not admitting of the Wound". The Gorgeous Nothings. The Envelope Poems of Emily Dickinson (courtesy of New Directions).

Sealing the coffin thus "fitted to a frame" 16 with a final "Perpetual nail," Dickinson erects a variant line on the right hand side border of the page, along the central fold of the envelope, wrapping up in turn the whole text: these "unsuspecting Carpenters" appear as a figure of the poet-builder of this space, the one who builds the "Possibility" Dickinson famously inhabits, "A fairer House than Prose." ${ }^{17}$ How to occupy a tight selfcontained space-including the space of this page-is clearly the poet's preoccupation here: the word "space," with its letters spaced out across the middle of the poem, is surrounded by a blank blurred by a variant word, "room," in smaller, more compact letters. This is Dickinson's line-breaking (as one would say "groundbreaking") visual rendering of the paradoxical gaping wound that contains the speaker's entire life, in Escher-like fashion like the Möbius strip, whose inside is simultaneously its outside: similarly, Dickinson creates a blank space filled out (or filled in, maybe) by the word "space"-a word that, additionally, turns out to be a variant of the previous line(s)-as modern editors interpret it, and as Miller's edition transcribes it: 
A not admitting of the wound

Until it grew so wide

That all my Life had entered it

And there were troughs beside -

A closing of the simple lid that opened to the sun Until the tender Carpenter

Perpetual nail it down -

(Dickinson 2016 M553) [there] was space $\cdot$ room

[simple] Gate

[the] sovereign $\cdot$ unsuspecting Carpenters

16 "rooms") is tentatively stitched by the variation on the spatial motif. Here again, the (de)lineation is key to understand the impossible postmortem position (or at the very least, a post-traumatic position) from which the persona speaks: the line break after "beside," itself followed by a dash acting simultaneously as opening and closure, introduces what should be the stanza break, but instead of a leap to the next line, we bifurcate into an alternative version, so that the adverb "beside" should be taken literally. By the side of the gaping wound, or inside its line, there lies a space, a hidden secret room, a ghost stanza, tautologically referring to the emptiness it points to and incarnates at the same time. Unsuspecting indeed were the carpenters who built the envelope for these shifting lines! As if to reassure herself on such an uncertain ground, Dickinson draws a firm line across the page, one that breaks the dangerously delinquent syntax of possibility. But the eye is drawn retrospectively to the other horizontal line appearing above, used for crossing out the word "troughs," only to repeat the very same word just under it: "And troughs there were" becomes "And there were troughs." Note that the print version chooses to ignore completely the crossing out of that word, as if it were insignificant; "troughs," however, refers to a hollow space that can be either natural (the trough of the sea is the hollow between waves) or manmade, or more specifically designed by a carpenter ("a large log or piece of timber excavated longitudinally on the upper side," according to Webster's dictionary). The visual uncertainty of these lines materializes the struggle to define, or confine, the wound hidden so long in plain sight that it can only be closed by the "simple lid" of death. Like the unsuspected wound the speaker would not admit in herself, the poem gapes in the middle, just opposite the narrowest part of the flap left blank in the envelope, which suddenly suggests that this might be the other space "beside," like an invitation to go around the unsuspecting carpenters and fill it in-all the more so since that adjacent space remaining blank might refer to the next world, as the allusion to a Christ-like situation, admittedly not entirely clear, suggests. Here again, Dickinson uses the envelope space strategically, filling it with a meaning well beyond that of a simple writing surface.

\section{Conclusions}

17 The specific space of the envelope, as reconstructed by Dickinson into a page of sorts, therefore shapes the material poetics of the line she engineers in her errant drafts. One has to take into consideration the subversion entailed by the lines penned on these surfaces, in an apparently casual, unprepared way which nonetheless contributes to altering the conventional spaces of inscription for poetry. As a last instance, let us focus on the following envelope, which initially contained a letter sent by Judge Otis P. Lord to the Dickinson sisters, Emily and Lavinia ("Vinnie"), possibly in 1882. It has been 
inscribed with text fragments penciled on both sides of the paper flattened out like a de-structured origami piece on the surface of which ink and pencil traces seem to jostle for attention (fig. 4 and 5).

\section{Fig. $4 \& 5$}

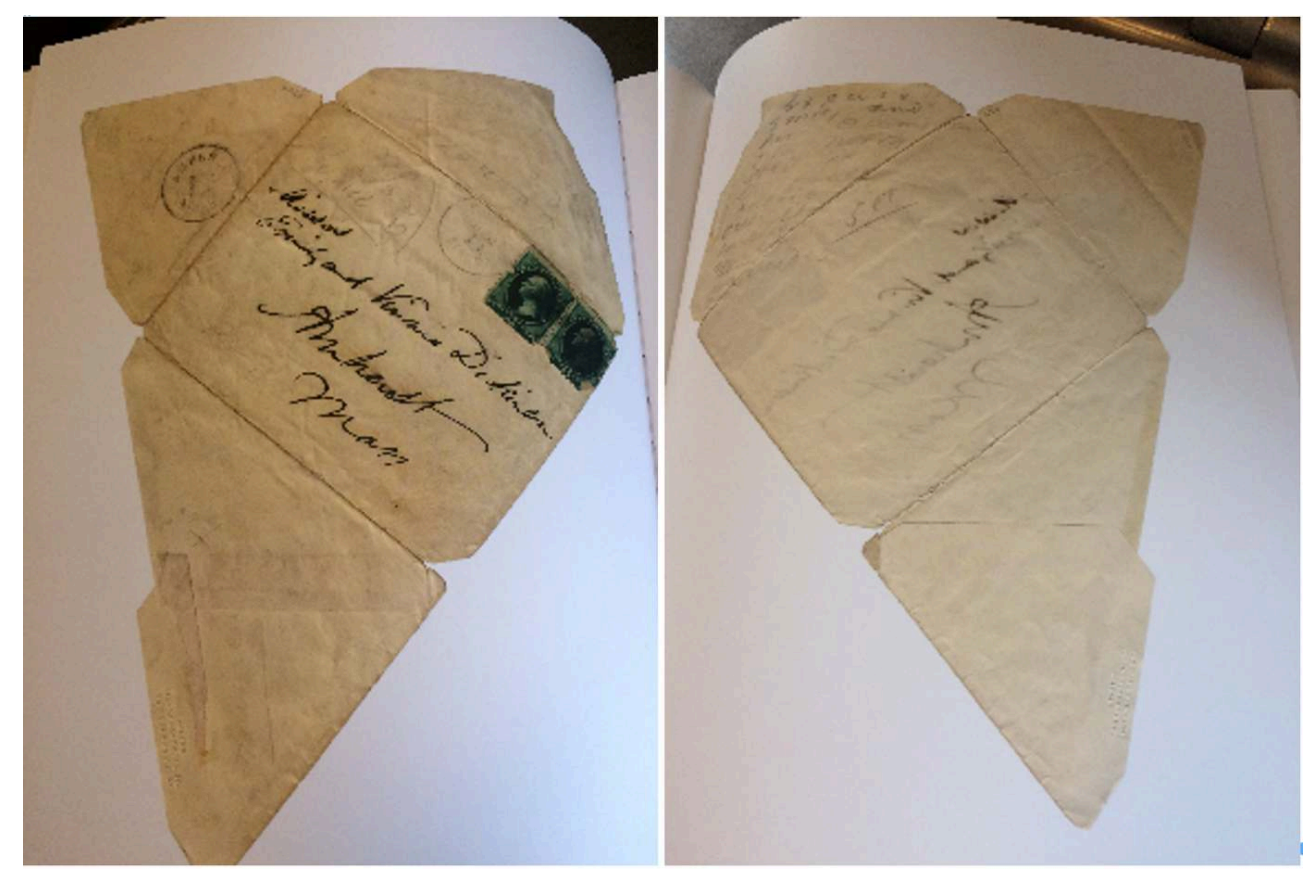

Outside and inside of the flattened out envelope for a letter addressed to the Dickinson Sisters by Judge Otis P. Lord. The Gorgeous Nothings. The Envelope Poems of Emily Dickinson (courtesy of New Directions)

Part of these added texts is a fragment of a message from Emily Dickinson to her sisterin-law, Susan Dickinson, written on the inside of one of the envelope's flaps (fig. 6): 
Fig. 6

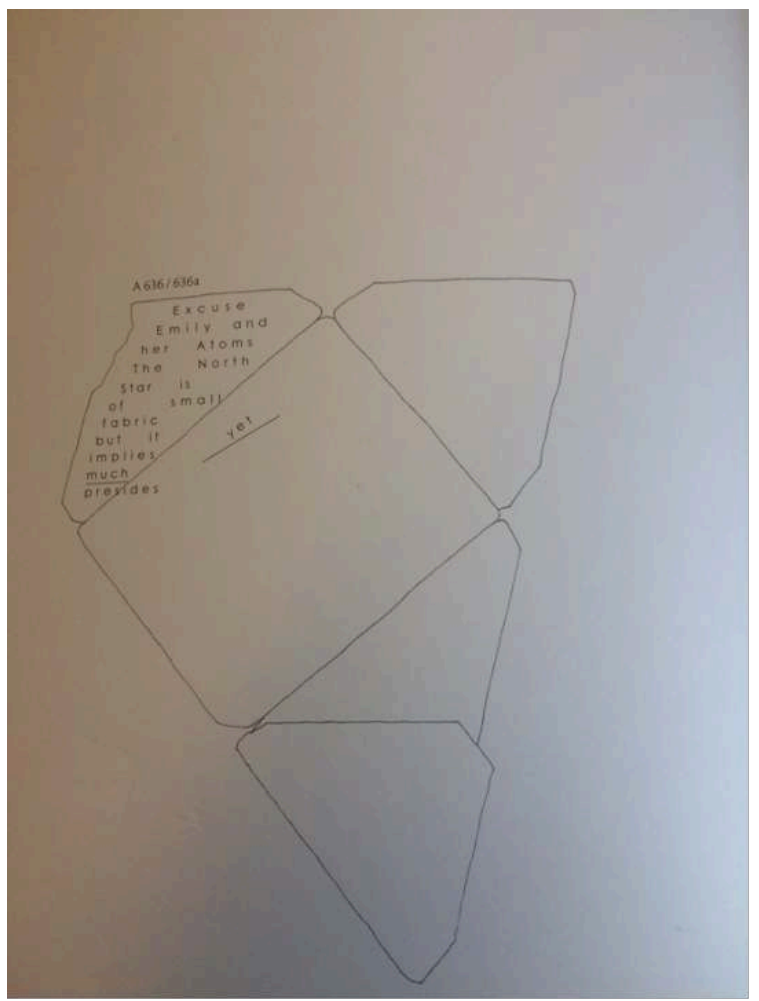

Transcript of the original shown in fig. 5. The Gorgeous Nothings. The Envelope Poems of Emily Dickinson (courtesy of New Directions). ${ }^{18}$

19 As can be seen, the lines are made to fit within the triangular shape of that cramped writing space, except for the last word, "presides," spilling over the fold into the main body of the envelope, where the underlined adverb "yet" stands out in startling isolation. "The writing is small in relation to the compositional space," notes Jen Bervin, "floating in its firmament. This poem [sic] exemplifies Dickinson's relationship to scale so perfectly" (Werner \& Bervin 8). Clearly, Dickinson's compositional strategy provides a material comment on her approach to issues of distance and greatness, privacy and fame: however small the corner in which "Emily" has penned herself, she intends her every atom to radiate like the North Star in the majesty of her oppositional solitariness, as this singular, and singularly detached, "yet" proclaims in a radical break out of line. Whether this fragment is a poem must remain undecided, but its unusual relationship to its space of inscription, together with its claim for the inherent greatness of "Atoms" and "small fabric," says something about the illicit circulation of lines from one correspondent to another. What line (of communication) gets broken when a poet chooses to write such an enigmatic note to her sister-in-law and next-door neighbor ${ }^{19}$ on the inside of an envelope initially addressed to her by a judge who was her known suitor? What contraband dealings in words does the envelope become the stage for?

On the outside of the same envelope, Dickinson jotted down fragments towards a poem, scattered in disjointed parts of the writing surface, referred to by Bervin as the "firmament"-a frequent Dickinson word, particularly used in her famous statement to Higginson to explain why she doesn't publish her poems: "I smile when you suggest that I delay 'to publish'-that being as foreign to my thought, as Firmament to Fin." 
(Dickinson, 1958 174) The very word actually appears in one of the fragments here, broken in such a way that it echoes the word "miracle," which seems to be the attracting center of these atomized stanzas (fig. $7 \& 8$ ).

Fig. $7 \& 8$

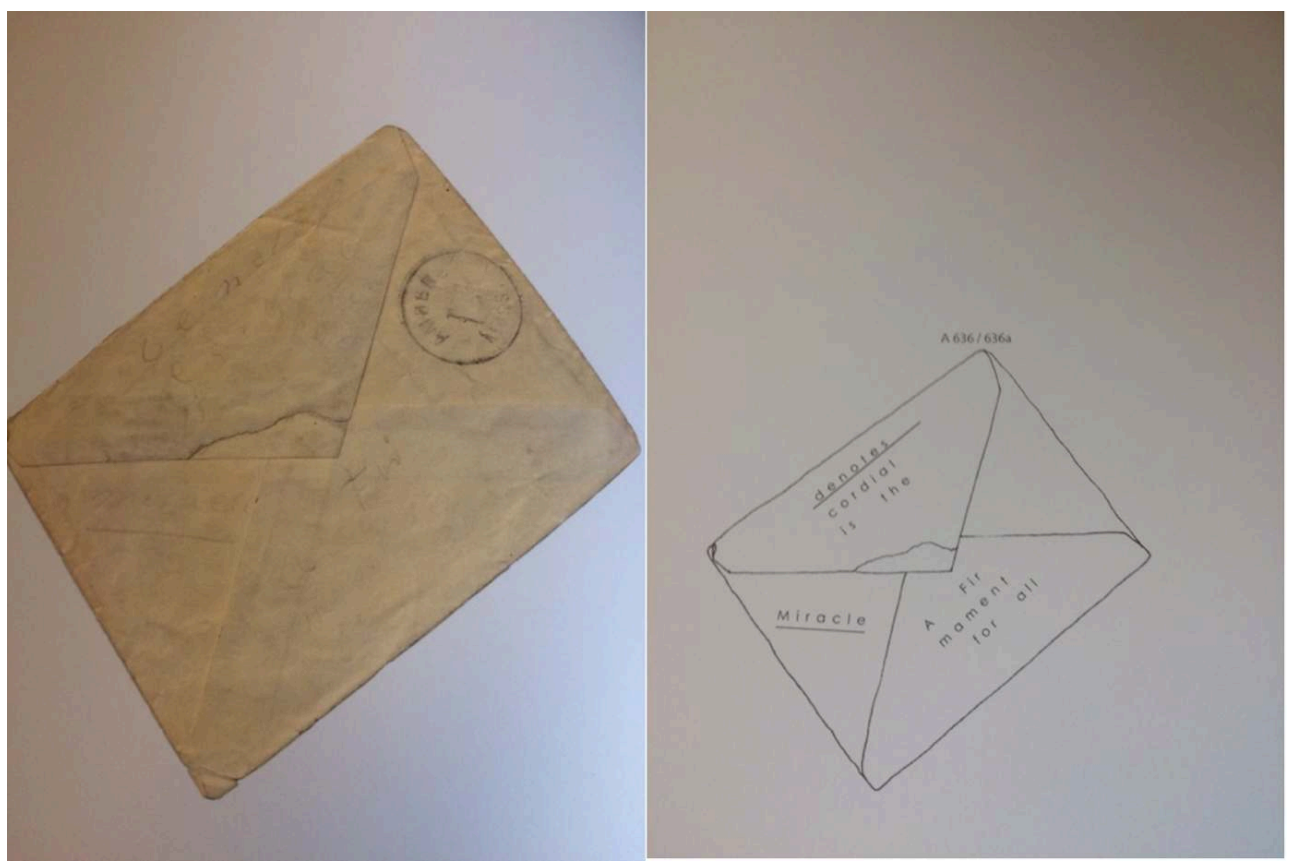

Original and transcript of the same folded envelope. The Gorgeous Nothings. The Envelope Poems of Emily Dickinson (courtesy of New Directions).

This line break splitting the word "Firmament" in two-an absolutely deliberate one, since it is not dictated by any spatial constraints-suggests that Dickinson's composition is not as random as it looks. Bervin and Werner's presentation makes that apparent in the last, refolded version of the envelope, wrapping up the fragments into a not-quite-yet formed poem, with the postal stamp facing the underlined word "Miracle" to balance the occupation of the four quadrants. It should be noted that parts of these lines would eventually find their way into the poem "Pompless no Life can pass away -" (J1626, Fr1594, M641), in particular "A Miracle for all" becoming its concluding line, while the line "How cordial is the Mystery!" in the "final" poem is still in the making on the envelope with "denotes cordial is the":

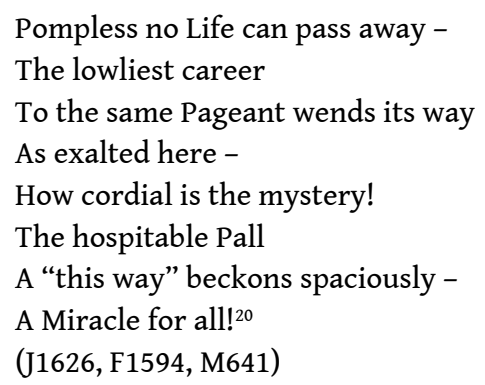

Unless of course "denotes cordial is the" is the complete broken line, away from which the so-called final version of the poem moves by padding it with an enticing "Mystery." What is left out of the broken line could be the untold/untellable secret that is passed on, not in an envelope, but at unexpected places on the outside of an envelope, 
disrupting the lines of communication, blurring the positions of the various addressees -Emily and her sister Lavinia, Susan, ${ }^{21}$ and the imagined reader of a poem-yet-to-be. Knowing or deciding who addresses whom is always a tricky thing in Dickinson's writings.

Bervin and Werner's edition of the envelope poems therefore raises the question of whether the original poem is these line-breaking, strategically broken lines, distilling the Myrrh out of the Miracle and the Fir out of the Firmament. In the final analysis, I would suggest that Dickinson's materialistic strategies of composition evidenced by the envelope poems boldly challenge the question of whether a poem evolves from a draft to a final version. The most strategic of her line breaks, made manifest in her choice not to publish, consists in leaving her readers with an array of possibilities for her texts -and we know that even in the poems copied cleanly in the Fascicles, when she most closely approximates a form of autonomous publication, she leaves possibilities open by using alternative words for many lines-thus allowing "Itineraries of Escape" to form, to take up Marta Werner's title to her interpretation of the envelope poems (Bervin \& Werner 197). In other words, these specific poems are a medium which embodies particularly well the editorial issues at stake in Dickinson's case. For, as our limited selection of examples has hopefully shown, Dickinson's poems are most of all characterized by their velocity and cannot easily be arrested in a fixed state. In her brilliant reading of Dickinson's envelopes repurposed to accommodate those fragments, Werner unravels the dynamics of correspondences presiding over the American poet's writing; Dickinson, she explains, "creates a template for flight that is also a trope for her late, contrapuntal communications, in which 'arrival' is another name for "departure"' (Bervin \& Werner 205). Caught mid-flight on the flaps of envelopes (or wings, as Werner perceives them to be), these poems approximate the condition of Dickinson's hummingbird in the poem she herself called by that title, entirely described in its movement as the only proof of its existence:

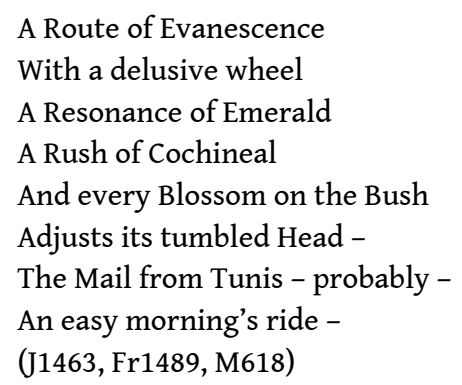

Both messenger and message, the bird-poem only lives as a trajectory whose coordinates are entirely dissolved in its own "Evanescence"; it exists in indirect traces of its movement back and forth, and is the circumference of its own energy, the vibration of its own velocity. Not by coincidence, this poem which concludes on an analogy with the epistolary was sent five (possibly six) times to various correspondents, in crisscrossing "routes" of distribution that disseminated it in several directions. Composed at a time (1879) when she had practiced the envelope poems for quite a while already (the earliest such poem included in The Gorgeous Nothings is dated ca. 1868-1870), "A Route of Evanescence" offers a variation on the combination of poem and letter so essential to the fluidity of Emily Dickinson's writing. It speaks to the economy of exchange which the reversed addressing performed by the envelope poems explore in a more experimental and secret manner. 


\section{BIBLIOGRAPHY}

AGAMBEN, Giorgio. The End of the Poem. Translated by Daniel Heller-Roazen. Stanford: Stanford University Press, 1999.

BERVIN, Jen. The Dickinson Composite Series. jenbervin.com/projects/the-dickinson-compositesseries\#2. Accessed 3 July 2021.

BERVIN, Jen, and Marta Werner, eds. The Gorgeous Nothings: The Envelope Poems of Emily Dickinson. New York: New Directions, 2013.

CRUMBLEY, Paul. Inflections of the Pen: Dash and Voice in Emily Dickinson. Lexington: The University Press of Kentucky, 1997.

DEPPMAN, Jed. Trying to Think with Emily Dickinson. Amherst: The University of Massachusetts Press, 2008.

DICKINSON, Emily. The Complete Poems of Emily Dickinson. Ed. Thomas H. Johnson. Cambridge, MA: The Belknap Press of Harvard University Press, 1955.

DICKINSON, Emily. Selected Letters. Eds. Thomas H. Johnson \& Theodora Ward. Cambridge, MA: The Belknap Press of Harvard University Press, 1958.

DICKINSON, Emily. The Complete Poems of Emily Dickinson. Ed. Ralph W. Franklin. Cambridge, MA: The Belknap Press of Harvard University Press, 1998.

DICKINSON, Emily. Emily Dickinson's Poems: As She Preserved Them. Ed. Cristanne Miller. Cambridge, MA: The Belknap Press of Harvard University Press, 2016.

Emily Dickinson's Archive. An Open-Access Website for the Manuscripts of Emily Dickinson. www.edickinson.org. Accessed 3 July 2021.

HAGENBÜCHLE, Roland. “Emily Dickinson's Poetic Covenant.” The Emily Dickinson Journal, vol. 2, no. 2, 1993, p. 14-39.

HART, Ellen Louise, and Martha Nell SMITH, eds. Open Me Carefully: Emily Dickinson's Intimate Letters to Susan Huntington Dickinson. Ashfield: Paris Press, 1998.

HOWE, Susan. "These Flames and Generosities of the Heart: Emily Dickinson and the Illogic of Sumptuary Values." The Birth-Mark: Unsettling the Wilderness in American Literary History. Middletown: Wesleyan University Press, 1993.

HOWE, Susan. Frame Structures. New York: New Directions, 1996.

McGANN, Jerome. Black Riders: The Visible Language of Modernism. Princeton: Princeton University Press, 1993.

MESSMER, Marietta. A Vice for Voices: Reading Emily Dickinson's Correspondence. Amherst: University of Massachusetts Press, 2001.

MILLER, Cristanne. Reading in Time: Emily Dickinson in the Nineteenth Century. Amherst: University of Massachusetts Press, 2012.

MONTGOMERY, Will. The Poetry of Susan Howe: History, Theology, Authority. London: Palgrave MacMillan, 2010.

OLSON, Charles. "Projective Verse." Collected Prose. Eds. Donald Allen and Benjamin Friedlander. Berkeley: University of California Press, 1997. 
SMITH, Martha Nell. "Suppressing the Books of Susan in Emily Dickinson." Epistolary Histories: Letters, Fiction, Culture. Eds. Amanda Gilroy and W.M. Verhoeven. Charlottesville: University Press of Virginia, 2000, p. 101-125.

SOCARIDES, Alexandra. Dickinson Unbound: Paper, Process, Poetics. Oxford: Oxford University Press, 2012.

WERNER, Marta. Radical Scatters: Emily Dickinson's Late Fragments and Related Texts, 1870-1886. http://radicalscatters.unl.edu. Accessed 3 July 2021.

\section{NOTES}

1. Published by New Directions, the book has the large format of an art book and the different elements of its composition keep a fine balance between the visible and the legible, including for instance a "Visual index" classifying the envelopes according to their shapes. Poised on the limit between the two modes, Marta Werner's transcripts of the facsimile manuscripts suggest how delicate their interactions can be, particularly by giving prominent visibility to the creases, folds and lines dividing the surfaces of the envelopes.

2. Dickinson's poetics includes definition as one of its major components. Her "definition poems" are many and startling. One of the most challenging of them states that "The Definition of Beauty is/That Definition is none -" (J1479, Fr1510, M500). The crucial point here is to literally dislocate the task of definition, which can no longer work as a conceptual formulation of space, but can only suggest in its radical negation (none) the erasure of the lines that might have allowed a notion to be contained within a finite envelope. This work of de-fining is encapsulated in Dickinson's paradoxical preference for "finite infinity" (although this famous line is not Dickinson's but an addition of her niece Martha Dickinson Bianchi, as the final line of "There is a solitude of space", J1695, Fr1696, M665). Accordingly, the exercise in negative definition of "The Definition of Beauty is" goes on, "Of Heaven, easing Analysis,/Since Heaven and He are One."

3. http://jenbervin.com/projects/the-dickinson-composites-series\#2 (last consulted 3/7/2021).

4. Radical Scatters is the title of Marta Werner's website presenting Dickinson's late writing, most of which was left in a state of apparently unfinished fragments: http://radicalscatters.unl.edu 5. But not for all of them, as shown by the recent print edition of the complete poems, the third to be published by Harvard University Press, prepared by Cristanne Miller (2016). It is important to notice that this edition was produced concurrently with the uploading online of all the manuscripts of Dickinson's poems, now accessible for free consultation on the Emily Dickinson Archive website (http://www.edickinson.org). In her meticulous scholarly edition, Miller did not reconstruct a putative chronology to organize the poems-unlike her two predecessors, T.H. Johnson (1951) and R.W. Franklin (1998)-but gave print transcripts that reflect Dickinson's own sequencing of the poems in her known "fascicles," adding further sections to present the numerous poems left by Dickinson in various stages of completion. Hence the title of her edition, Emily Dickinson's Poems, As She Preserved Them. The choice of arranging the variant words, characteristic of Dickinson, on the right hand side of the poems, rather than at the bottom of the page as was Dickinson's common practice, is of course debatable on visual grounds. Miller's latest critical book on Dickinson, Reading in Time, is overall a clear statement that, for her, Dickinson's lines (and poetry, more generally) are not ruled by visual parameters, but rather by prosodic ones: "My reasoning leaves aside all questions of the look of the manuscript page" (Miller, 2012 11). For the writing of that book, Miller scanned the entire corpus of Dickinson's verse, thus revealing a wide variety of metrical patterns. Such a critical and editorial positioning has wideranging consequences as to the very nature of Dickinson's texts (including her letters). In this 
context, the envelope poems provide a body of texts that sit undecidedly between visually ruled and metrically determined, in a very experimental fashion.

6. "Dickinson's one surviving dress has a large external pocket on the right side, where her hand would fall easily and rest. The economy of the pocket is worth considering. An envelope is a pocket. An envelope refolds discreetly, privately, even after it has been sliced completely open" (Bervin \& Werner 12).

7. "False impression" could easily be read as a pun here. Without detracting from its substance, it must be underlined that Hagenbüchle's judgment is inevitably dated, since only the first scholarly edition of Dickinson's poems edited by Thomas Johnson was available at the time he wrote, while Ralph Franklin had already published his facsimile edition of Dickinson's manuscripts (1986), providing Hagenbüchle the means to discern the visual value at work in her writing. But Franklin's and Miller's editions have not substantially changed the game.

8. We refer to Dickinson's poems throughout according to the common scholarly practice: in Johnson's (J) and Franklin's (F) editions, the poems are numbered by the editors, while in Miller's (M), the numbers stand for the page.

9. The manuscript can be seen here: https://www.edickinson.org/editions/2/image_sets/ 12169398 (last consulted 3/7/2021).

10. In Dickinson's cherished Webster's dictionary, one of the definitions of the word "line" specifically refers to its biblical meaning: "23. In Scripture, line signifies a cord for measuring; also, instruction, doctrine. Psalms 19:4. Isaiah 28:10." (http://webstersdictionary1828.com/ Dictionary/Line, last consulted 3/7/2021). Dickinson's poetic project of line breaking most certainly included fundamental deviations from the line of orthodox religious thought, and one might say that her "odd" (unusual, irregular) poetry lines were a textual manifestation of her exception from instruction and common doctrine, as much as from the common meter used in Wyatt's hymns.

11. Etymology tells us that "secret" also has to do with lines, since it comes from an IndoEuropean root word meaning "separate, cut off," also to be found in "harvest" amongst others. One of Susan Howe's earliest poetry sequences is entitled Secret History of the Dividing Line (Howe, 1996 87-122).

12. In his comprehensive study of Dickinson's dashes, Paul Crumbley was one of the earliest scholars to invite thinking about how the two interact: "any determination of the way to read lines depends entirely on how dramatically we as readers interpret the disjunctions represented by dashes" (Crumbley 23), he writes, clearly giving the dashes the status of a meta-interpretative operator as he notably promotes their visual aspect on the page to a meaning-making function.

13. "First, some simplicities that a man learns, if he works in OPEN, or what can also be called COMPOSITION BY FIELD, as opposed to inherited line, stanza, over-all form, what is the "old" base of the non-projective" (Olson 239). Similarly, McGann notes that "Franklin's edition [of The Manuscript Books of Emily Dickinson] makes it clear that Dickinson's texts are what would later be called (by Charles Olson) 'composition by field.' The grouping of the poems into fascicles corresponds to a similar approach to the text at a more local level-a poetic deployment of writing within the given space of the page" (McGann 27).

14. "Let's start from the smallest particle of all, the syllable. It is the king and pin of versification, what rules and holds together the lines, the larger forms, of a poem. ... It is by their syllables that words juxtapose in beauty, by these particles of sound as clearly as by the sense of the words which they compose. In any given instance, because there is a choice of words, the choice, if a man is in there, will be, spontaneously, the obedience of his ear to the syllables. ... It would do no harm, as an act of correction to both prose and verse as now written, if both rime and meter, and, in the quantity words, both sense and sound, were less in the forefront of the mind than the syllable, if the syllable, that fine creature, were more allowed to lead the harmony on" (Olson 241 , ellipses mine). 
15. Dickinson's famous poem "It was not Death, for I stood up," (J510, Fr355, M187) also concludes on the absence of land to confirm the total lack of hope she has been trying to define, albeit negatively, throughout her lines: "But most, like Chaos - Stopless - cool - / Without a Chance, or spar - / Or even a Report of Land - / To justify - Despair.” (last stanza)

16. See Emily Dickinson's "It was not Death, for I stood up" (J510, Fr355, M187): “As if my life were shaven/And fitted to a frame".

17. "I dwell in Possibility -/A fairer House than Prose -" (J657, Fr466, M233). In a less optimistic perspective, they might also be seen as coffin builders.

18. As suggested above (see note 1), Werner and Bervin's editorial decision to include a transcription for every envelope, respecting the spatial arrangement of the words, is quite unique. Their choice of a light font reflects the "small fabric" of Dickinson's handwriting.

19. The complex relationships between the two houses on the Dickinson estate, The Homestead (where Emily lived) and The Evergreens (home of Austin and Susan Dickinson), has been amply documented, particularly in the light of the steady exchange of letters between Emily and Susan Dickinson, even as they lived barely a hundred yards apart. It might not be too far-fetched to hear an At Homes behind these Atoms-at this late stage of her life, Emily Dickinson was no longer leaving The Homestead. For a selection of the correspondence between Emily and Susan Dickinson, see Hart and Smith. Marietta Messmer's A Vice for Voices: Reading Emily Dickinson's Correspondence is a key study of Dickinson's epistolary practice.

20. The connection between these envelope fragments and "Pompless no Life can pass away -" is made by Werner (Werner \& Bervin 250), following Franklin's lead (Dickinson, 1998 1393-4), but not by Miller.

21. It is important to remember that Susan Dickinson became early on Emily's "consultant, collaborator, confidante" (Smith 112).

\section{ABSTRACTS}

By taking a close look at the poems Emily Dickinson wrote, in the last fifteen years or so of her life, on envelopes (as gathered and transcribed in The Gorgeous Nothings, edited by Marta Werner and Jen Bervin), this article addresses the question of writing on a constrained surface-itself riddled with vertical, horizontal and oblique lines acting as so many "breaks." How did Dickinson tackle the material space of inscription in (de)composing her poems? The often playful way in which she stages her line breaks indicates how aware she was of the relationship between her words and their various poetic "envelopes." Here, the materiality of the medium becomes part of the meaning of the poems, and further contributes to the fluidity with which Dickinson positions her writing on the limits between the poetic and the epistolary.

À travers l'analyse de quelques poèmes qu'Emily Dickinson écrivit sur des enveloppes durant les quinze dernières années de sa vie - poèmes rassemblés et transcrits par Marta Werner et Jen Bervin dans The Gorgeous Nothings -, cet article travaille la question de l'écriture sur une surface contrainte, elle-même barrée de lignes horizontales, verticales et obliques qui fonctionnent comme autant de "sauts de ligne». Comment Dickinson aborde-t-elle l'espace d'inscription matérielle de ses textes lorsqu'elle les (dé)compose ? Sa façon souvent ludique de mettre en scène les retours à la ligne suggère à quel point elle a conscience de la relation qui unit ses mots à leurs diverses « enveloppes » poétiques. Ici, la matérialité même du médium se fait partie intégrante 
du sens et contribue à la fluidité dont fait preuve Dickinson pour situer son écriture aux limites du poétique et de l'épistolaire.

INDEX

Mots-clés: Emily Dickinson, enveloppe, épistolaire, matérialité poétique, saut de ligne, versification

Keywords: Emily Dickinson, envelope, epistolary, poetic materiality, line break, lineation

\section{AUTHOR}

ANTOINE CAZÉ

Université de Paris - LARCA UMR CNRS 8255 